\title{
DEVELOPMENT AND TRIBOLOGICAL CHARACTERIZATION OF FLY ASH REINFORCED IRON BASED FUNCTIONALLY GRADIENT FRICTION MATERIALS
}

\author{
Kasi Rajesh Kannan - Ramalingam Vaira Vignesh - Kota Pavan Kalyan - Myilsamy Govindaraju* \\ Department of Mechanical Engineering, Amrita School of Engineering, Coimbatore, Amrita Vishwa Vidyapeetham, \\ India.
}

\begin{tabular}{l}
\hline ARTICLE INFO \\
\hline Article history: \\
Received \\
Received in revised form \\
Accepted \\
\hline Keywords: \\
friction materials, \\
FGM, \\
powder metallurgy, \\
tribology \\
\hline DOI: https://doi.org/10.30765/er.1501
\end{tabular}

\footnotetext{
* Corresponding author

E-mail address: m_govindaraju@ch.amrita.edu
}

\begin{abstract}
:
The tribological and thermal properties enable iron based sintered materials with hard phase ceramic reinforcements as promising friction material for heavy-duty wind turbines. In wind turbines, the braking system consists of aerodynamic and mechanical braking systems. During application of mechanical brakes, the friction materials are pressed against the rotating low-speed shaft. The desired braking efficiency is achieved by utilizing a number of friction materials, which in turn are joined in a steel backing plate. Though this arrangement increases the braking efficiency, the hard phase ceramic reinforcement particles reduces the bonding strength between the friction material and steel backing plate. The joint failure leads to catastrophic failure of wind turbine. Therefore, the need of the hour is to develop friction materials with functional gradients that have high wear resistance (contact area) and high bond strength (interface). In this study, an attempt is made to fabricate and characterize a friction material with gradient profile of composition along the cross section to provide functional gradient property. The functional gradient friction material is synthesized by gradient deposition of $\mathrm{Fe}, \mathrm{Cu}, \mathrm{Cg}, \mathrm{SiC}$ and fly ash powders which is then compacted and sintered. The prepared functional gradient friction material was characterized in terms of microstructure and microhardness. The tribological performance (wear rate and coefficient of friction) of the developed functionally gradient friction material was investigated at various loads using pin-on disc apparatus. The results show that as the load increases, the wear rate decreases and at the same time the COF tends to increase at higher loads. The predominant wear mechanism was deduced from the morphology of the worn surface.
\end{abstract}




\section{Introduction}

Wind power is a clean, effortlessly available, and a renewable energy source that plays a mandatory role in the global energy mix. Wind turbines comprises of rotor blades, generator, transmission system and braking system, which helps in wind tapping and conversion of wind energy to electrical energy. Safety and durability of the wind turbines depends on the condition of the systems and hence periodic maintenance prevents the breakdown failure of the wind turbines. One of the challenging segments in the wind turbine is the braking system. On the instance of extreme wind velocities or emergency conditions, the braking system plays vital role in preventing the wind turbines from catastrophic failures. Generally, the wind turbines have two braking systems: aerodynamic braking system and mechanical braking system.

Aerodynamic brakes are the foremost braking that reduces the rotational motion by altering the distribution of pressure in the wind turbine blades. Mechanical brakes are the secondary brakes that comprises of friction materials (brake pads). Brakes are employed to resist a moving body either mechanically or hydraulically such that the motion is arrested by the absorption of energy from the system. Innovative friction materials are developed using alloys, composites and sintered metallic materials to meet working parameters such as pressure, temperature, speed and specific application requirements.

The characteristics of the friction materials are determined and are analyzed based on their ability to bear load, resist wear, and yield an optimum and stable coefficient of friction (COF) along with better thermal and mechanical properties. These materials should be cost effective and the fabrication method should be feasible.

Currently, researchers are involved in developing innovative friction materials using powder metallurgy technique with such desired properties. The constituents of the friction materials include metals, hard phase ceramics, and additives (lubricants, friction modifiers) to improve the wear resistance, thermal stability, and optimum COF. Number of friction materials are joined on a steel substrate and are pressed against the disc (low speed shaft) to achieve the braking efficiency. However, the joint strength is deterred by the ceramic particles that may lead to catastrophic failure of the wind turbines. This necessitates is the development of material with good joint strength in the substrate and high wear resistance at the contact surface. This unique class of materials known as functionally gradient materials will deliver this distinctive functionality.

Functional gradient materials (FGMs) are composite materials that exhibit progressive variation in composition, microstructure, and properties along their cross-section. Research on FGMs is increasing day by day due to their excellent properties. Powder metallurgy is one of the feasible, economical, and suitable ways for the fabrication of FGM with microstructural and compositional control along with shape formation. The fabrication of layered FGM components are very challenging by casting or conventional metal forming processes. Powder metallurgy involves mixing powders (metals, ceramics or compounds) and then compacting and sintering them under vacuum or in a controlled environment.

Alberto et al. [1] found that $\mathrm{Cu}$ based sintered friction material with $\mathrm{Fe}, \mathrm{Sn}, \mathrm{Cg}$, and $\mathrm{SiO}_{2}$ exhibited a higher COF (0.36) than that of the real-time wind turbine friction material (0.30). The inclusion of $\mathrm{SiO}_{2}$ improved the COF of the sintered specimen. The investigation of Balamurugan et al. [3] indicated that the specimen with 10 wt.\% FA exhibited a maximum hardness of $175 \mathrm{Hv}$. However, a low wear rate $\left(7 \times 10^{-}\right.$ ${ }^{4} \mathrm{~mm}^{3} / \mathrm{m}$ ) was observed for the specimen with 5 wt.\% FA. Kang [5] inferred that the wear and friction properties relies on the surface softening effect, transfer of materials, and formation of friction film. Besides, the results indicated that $\mathrm{Cu}$ based specimens exhibited unsteady $\mathrm{COF}$ of 0.5 at high loads and $\mathrm{Fe}$ based specimens provided stable COF (0.2-0.3) at high speed and load.

Surojo et al. [2] inferred that COF of composite brake shoes increased (0.5) with increase in FA content (10\%). The automotive brake lining with FA and Cg (5\%) developed by Samrat Mohanty et al. [4] exhibited a stable COF (0.35-0.40) because of thermal resilience and better lubrication. Narasimhan [6] found that the solubility of copper in $\mathrm{Fe}$ is about $5 \%$ at $2 \% \mathrm{Cu}$ addition. Inclusion of $\mathrm{Cu}, \mathrm{Cg}$ in the $\mathrm{Fe}$ matrix can improve tensile strength, hardness, and wear resistance.

The experimental investigations of Merie et al. [7] indicated that the inclusion of $\mathrm{TiO}_{2}$ up to $6 \%$ had no significant effect on $\mathrm{COF}$ in $\mathrm{Fe}$ based brake pad. However, specimen with $8 \% \mathrm{TiO}_{2}$ exhibited a decrease in the COF (0.387). Chandrasekaran et al. [8] established that the specimen ( $\left.\mathrm{Fe}-\mathrm{Cu}-\mathrm{Sn}-\mathrm{Pb}-\mathrm{MoS}_{2}\right)$ with $7.5 \% \mathrm{~Pb}$ exhibited high strength, hardness, and wear resistance. The experimental investigation on $\mathrm{Fe}^{-} \mathrm{Al}_{2} \mathrm{O}_{3}$ composite reinforced with $\mathrm{CoO}$ by Gupta et al. [9] inferred that the hardness values increases due to presence 
of $\mathrm{Al}_{2} \mathrm{O}_{3}$. In addition, doping of $\mathrm{CoO}$ on $\mathrm{Fe}-\mathrm{Al}_{2} \mathrm{O}_{3}$ composite resulted in adhesive wear under $1.5 \mathrm{~kg}$ load and abrasive wear for $2.0 \mathrm{~kg}$ load.

The studies of Gulsoy et al. [10] showed that inclusion of B in Fe based brake pads induced liquid phase sintering and hence resulted in high density, high hardness and low wear rate $\left(15 \times 10^{-9} \mathrm{~mm}^{3} / \mathrm{Nm}\right)$. Tekeli et al. [11] found heat-treated $\mathrm{Fe}$ samples with $0.3 \%$ graphite and $2 \% \mathrm{Ni}$ exhibited good wear resistance $\left(0.5 \times 10^{-}\right.$ ${ }^{12} \mathrm{~m}^{3} / \mathrm{m}$ ). Gopinath [12] inferred that the sintered $\mathrm{Fe}-\mathrm{Cu}$ samples showed a mild wear rate of $0.2 \mathrm{~g}-0.4 \mathrm{~g}$ under sliding velocity less than $8 \mathrm{~m} / \mathrm{s}^{-1}$. However, beyond and above that it showed severe wear rate of $1.5 \mathrm{~g}$ for sintered iron and and $0.77 \mathrm{~g}$ for $\mathrm{Fe}-5 \% \mathrm{Cu}$ and $0.6 \mathrm{~g}$ for $\mathrm{Fe}-5 \% \mathrm{Cu}-5 \% \mathrm{Cg}$.

Ram Prabhu et al. [13] found that $\mathrm{SiC}$ addition helps in hardness improvement and wear resistance of the monolayer composite is less as compared with multi-layered composite. During braking speed of $25 \mathrm{~m} / \mathrm{s}$, abrasive wear phenomenon was encountered, and at higher speeds above $30 \mathrm{~m} / \mathrm{s}$, delamination, oxidation wear was observed and COF was around 0.30. Nadjafi Maryam Negari et al. [14] inferred that the maximum hardness of $95 \mathrm{HV} 5$ and density of $7.3 \mathrm{~g} / \mathrm{cm}^{3}$ were obtained for $\mathrm{Fe}$-microwax based samples and $\mathrm{Fe}-$ microwax-Cu samples showed a lesser density value $\left(6.3 \mathrm{~g} / \mathrm{cm}^{3}\right)$. Microstructural studies reveals that the pores were delicate and particles were homogeneously distributed, which leads to the strength and density improvement.

The experiments by Peter Ildiko et al. [15] on $\mathrm{Fe}, \mathrm{Cu}$, Bronze, $\mathrm{Cg}, \mathrm{SiC}, \mathrm{Al}_{2} \mathrm{O}_{3}, \mathrm{ZrSiO}_{4}$ composites and found that $\mathrm{Cu}$ based samples had poor joint strength as compared to Fe based samples. Sintered materials $\left(\mathrm{Cu}\right.$ and bronze or Fe and bronze showed a lower wear rate $\left(0.8 \times 10^{6} \mathrm{~kg} / \mathrm{cm}^{3}\right)$ and COF was around 0.4-0.5. Studies on Fe-SiC powder blending by Cheekur Krishnamurthy Srinivasa et al. [16] concluded that the density increases with decrease in $\mathrm{SiC}(1 \mathrm{wt} \%)$ content $\left(7.80 \mathrm{~g} / \mathrm{cm}^{3}\right)$ and microhardness increases $(475 \mathrm{VHN})$ with increase in $\mathrm{SiC}(5 \mathrm{wt} \%)$ content.

Ugur Cavdar et al. [17] inferred that $\mathrm{Fe}-\mathrm{Cu}$ - Zinc stearate based samples with $3 \% \mathrm{Cu}$ showed higher hardness $188 \mathrm{HV}$ and $\mathrm{Fe}$ samples with $6 \% \mathrm{Cu}$ showed higher density $\left(6.6 \mathrm{~g} / \mathrm{cm}^{3}\right)$. Results of Oliveira et al. [18] on $\mathrm{Fe}-\mathrm{Cu}-\mathrm{SiC}$ composites revealed that samples with $\mathrm{SiC}$ content showed a high hardness value and nearly $14 \%$ increase of hardness value than that of $\mathrm{Fe}-\mathrm{Cu}$ system $(32 \mathrm{HB})$. Sintering at $1150^{\circ} \mathrm{C}$ temperature promotes effective liquid phase sintering, and $\mathrm{Cu}$ addition in $\mathrm{Fe}$ improves the hardness values.

$\mathrm{KeKe} \mathrm{Gan}$ et al. [19] concluded that addition of Fe increases the strength of the $\mathrm{Cu}-\mathrm{SiCp}-\mathrm{Fe}$ composites from $246 \mathrm{MPa}$ to $362 \mathrm{MPa}$. Fe inclusion promotes densification of $\mathrm{Cu}$ atoms inter diffusion that reduces porosity and improves strength.

Results of Yilmaz et al. [20] on $\mathrm{FeCr}\left(\mathrm{M}_{7} \mathrm{C}_{3}-\mathrm{M}_{2} \mathrm{C}_{6}\right)$, Copper and graphite revealed that abrasive wear decreased with reinforcement addition. $10 \% \mathrm{FeCr}$ samples shows a maximum hardness of $120 \mathrm{BH}$ further copper addition from $0.5-2 \mathrm{wt} \%$ improved the hardness up to $224 \mathrm{HB}$. Cg, a promising solid lubricant inclusion at a range of $0.25-2 \mathrm{wt} \%$ improved hardness and increase in $\mathrm{Cu} w \mathrm{wt} \%$ reduce the wear rate with a mass loss of $0.2 \mathrm{mg}$ as compared with samples with less amount of $\mathrm{Cu}$.

The brief literature review illustrates that most of the friction materials studied for heavy duty applications are composite materials. It also highlights a persistent gap in the development of functional gradient materials for high performance friction materials. The main objective of this research is to develop a friction material that has high wear resistance at the contact surface and good adhesion with the steel backing plate. The research investigates the microstructure, microhardness and wear resistance of the developed functional gradient friction material. Ultimately, it was found that the developed material has a low wear rate at higher loads and the COF increases with increasing load. The characterization of the worn surface was carried out using FESEM.

\section{Materials and Methodology}

\subsection{Materials}

In this research work, metallic and ceramic powders were acquired from prominent suppliers. $\mathrm{Fe}(99.9 \%)$ with a particle size of 100 mesh, $\mathrm{Cu}(99.9 \%)$ with a particle size of 100 mesh, graphite powder, SiC with a particle size of 30-50 micron and fly ash was used. The particle size of the powders and purity was analyzed. 
Desirable properties of the composites can be obtained by the gradient formulation of the composition. Precision weigh balance with a readability of $0.0001 \mathrm{~g}$ was used to measure the powder weight. To increase the green strength of the compacts, $\mathrm{PVOH}$ was used as a binder. Before mixing, powders were ball milled separately, and after proper formulation, again ball milled. This technique was done to mix $\mathrm{Fe}$ homogeneously, $\mathrm{Cu}, \mathrm{SiC}, \mathrm{Cg}$, fly ash powders. Ball milling operation involves mixing of powders in a stainless steel container with 42 tungsten balls for a period of $1 \mathrm{hr}$ at 250rpm. These homogeneously mixed powders were cold compacted in a cylindrical die of $20 \mathrm{~mm}$ dia. These green compacts were sintered under controlled $\mathrm{H} 2+$ Argon atmosphere for a period of 45 minutes at $1080^{\circ} \mathrm{C}$ at the heating rate of $8^{\circ} \mathrm{C} / \mathrm{min}$. Sintering time-temperature graph is shown in Figure (1).

\subsection{Microstructure}

As per ASTM E3-11 standards, the sintered specimens were prepared for microstructure studies. Sintered samples were polished in different metallographic sheets of grit 400,600, 800, 1000, 1500. After polishing, microstructure studies were investigated using optical microscope (Make: Carl Zeiss, Model: Axiovert 25).

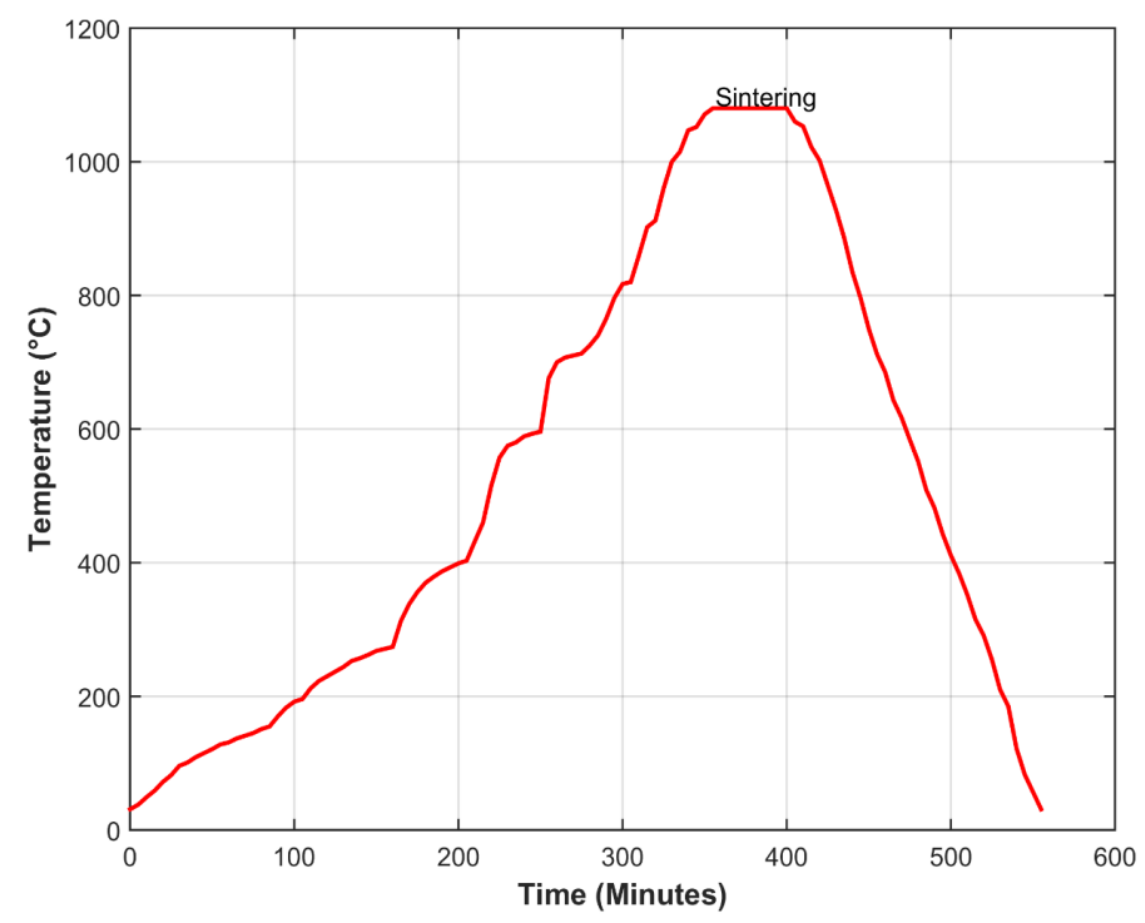

Figure 1. Time versus Temperature - Sintering of FGM.

\subsection{Microhardness}

Samples to be tested for microhardness measurements were prepared as per ASTM E3-11 standards. Vicker's microhardness of the sintered specimens were obtained using (Make: Mitutoyo; Model: HVT - M1) microhardness tester. Hardness tests were performed by the application of $100 \mathrm{~g}$ normal load for a dwell period of 15 seconds. The average microhardness of the each layer that was measured at ten different locations was reported.

Tribological Characterization

Tribological characteristics of the sintered specimens were done on pin-on-disc wear apparatus (Make: Ducom; Model: TR-2OLE-PHM-200) as per ASTM G99-5a. Sintered specimens (three specimens for each load) of $20 \mathrm{~mm}$ diameter were mounted in a hollow stainless steel tube utilizing cold setting compound. An ultrasonicator with ethanol was used to clean the samples. Specimens were mounted on the tribometer against the counter disc made of EN-31 steel. Wear test parameters were chosen as follows sliding velocity of $5.5 \mathrm{~m} / \mathrm{s}$ and sliding time of 10 minutes. With the help of lever arrangement set up, samples were tested by 
the application of a normal load of $5 \mathrm{~kg}$ and $10 \mathrm{~kg}$. The specimens were cleaned and were weighed in a precision weighing with a readability of $0.0001 \mathrm{~g}$ to calculate the mass loss after the wear test.

Characterization using Analytical Instruments

Worn surface morphology of the specimens were analyzed using field emission scanning electron microscopy with appropriate voltage acceleration. X-ray diffraction analysis was studied using X-ray diffractometer (Make: Rigaku; Model: Ultima 4) that reveals the phase formation in the sintered specimens. Sintered specimens were scanned at the rate of $0.5^{\circ}$ per minute using continuous scanning mode at $\mathrm{Cu}-\mathrm{K} \alpha$ radiation.

\section{Results and Discussion}

\subsection{Microstructure}

Microstructure of the layered FGM specimen is shown in Figure (2) that gives a clear picture of the gradient layers. The first gradient layer comprises of $\mathrm{Fe}-15 \% \mathrm{Cu}-2 \% \mathrm{Cg}-2 \% \mathrm{SiC}-4 \% \mathrm{Fly}$ ash where exists a dense region of hard particles that promotes wear resistance and the bottom-most coat comprises of copper that provides a good bonding strength with steel back plate. Graphite inclusion helps in improving thermal stability and optimizes the $\mathrm{COF}$. Fly ash and $\mathrm{SiC}$ are stable at high sintering temperature, and it increases the hardness and wear resistance of the materials.
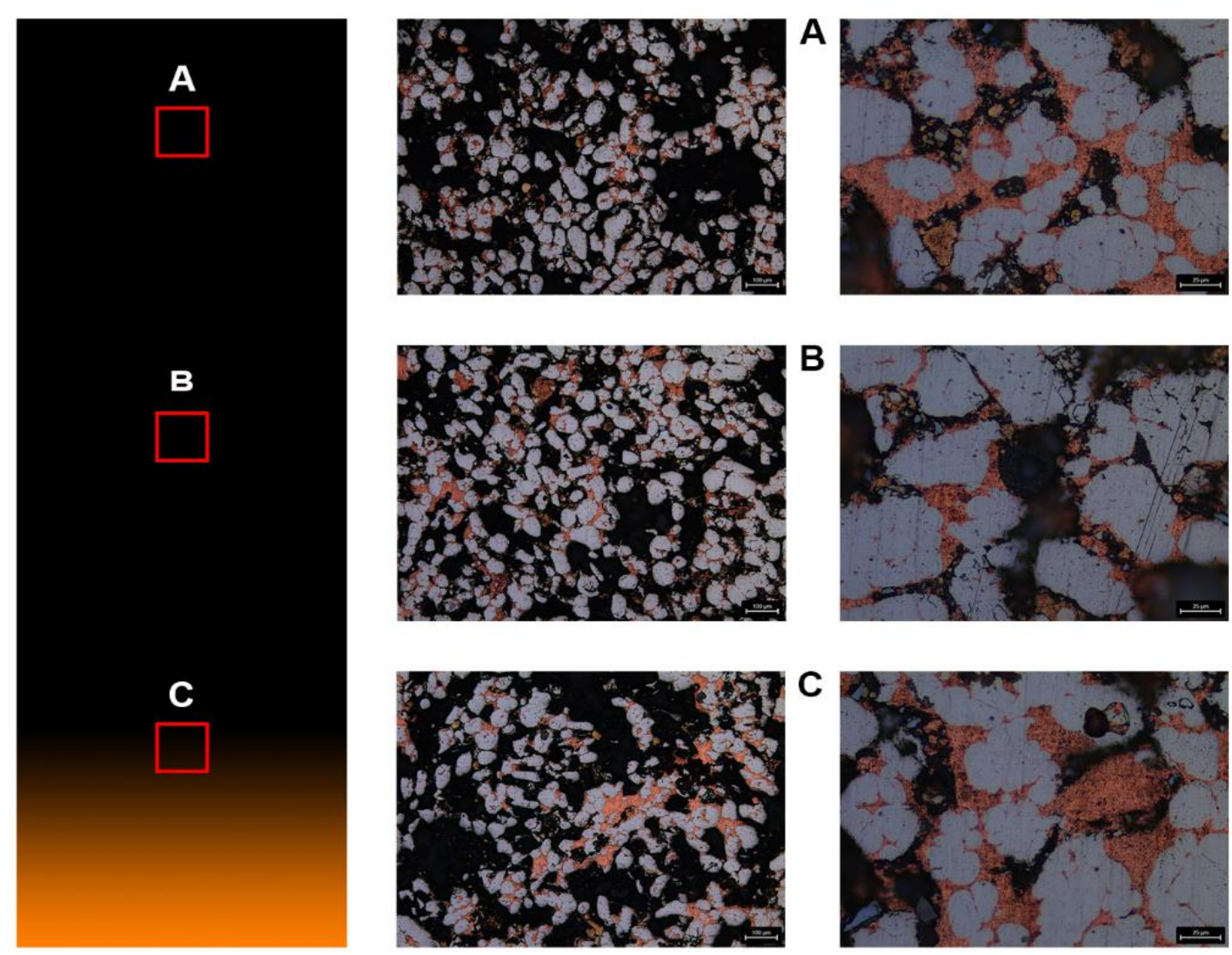

Figure 2. Microstructure of the sintered FGM. 


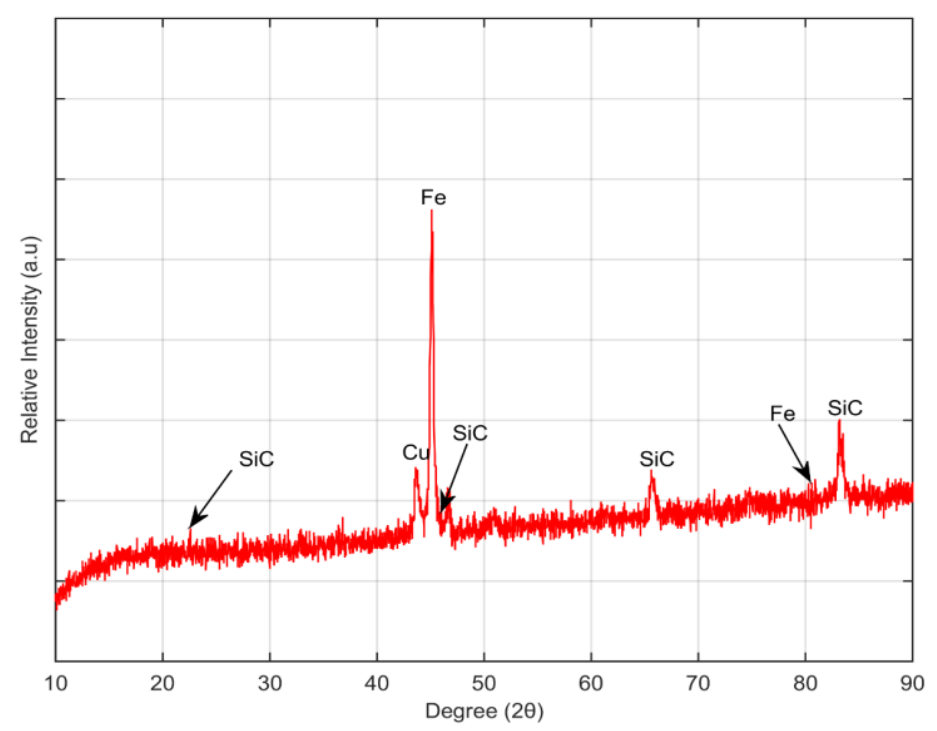

Figure 3. X-Ray Diffraction graph of the sintered FGM.

XRD graph of the sintered FGM is shown in Figure (3). Major peaks were identified for $\mathrm{Cu}, \mathrm{Fe}, \mathrm{Cg}, \mathrm{SiC}$.

\subsection{Microhardness}

For microhardness values of the sintered specimens, Vicker's microhardness tester was used. Hardness values were obtained by applying a normal load of $100 \mathrm{~g}$ along the traverse section of the sintered specimen.

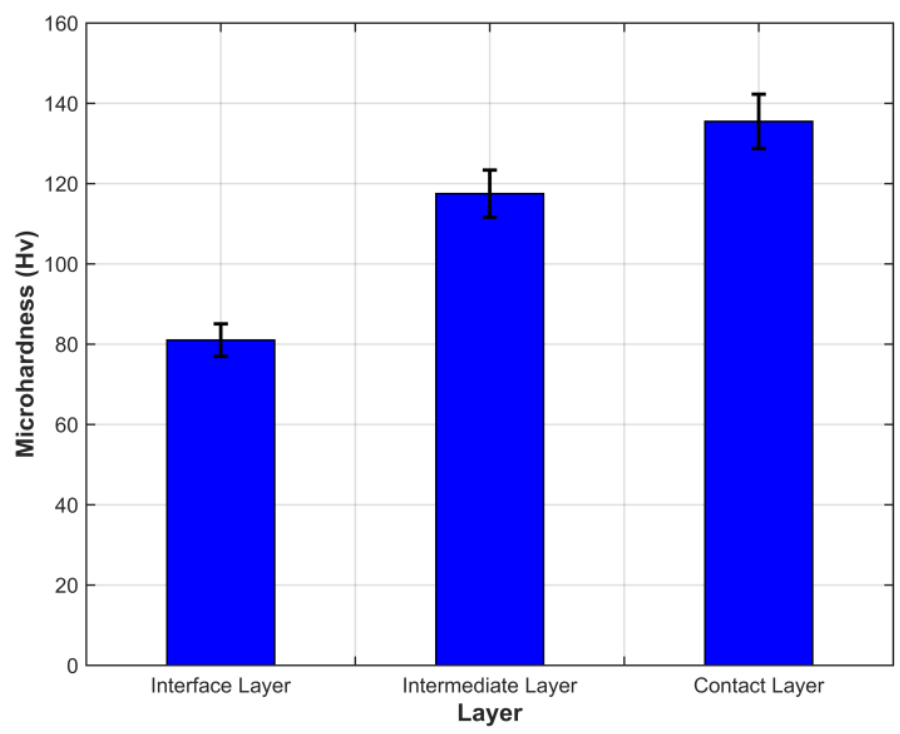

Figure 4. Microhardness of the layered FGM.

An average of ten measurements were taken at different spots in each layer of the specimen. The topmost (contact) layer comprising of hard particles showed an average hardness of $137 \mathrm{Hv}$. At the intermediate layer, an average hardness of $118 \mathrm{Hv}$ was observed. An average hardness of $83 \mathrm{Hv}$ was observed at the bottommost (interface) layer, because of low fraction of hard particles. Figure (4) shows the hardness profile of the developed specimen.

\subsection{Tribological Characterization}




\subsubsection{Wear rate}

Wear rate and COF of the specimens were determined using Pin-on-disc testing rig under normal loads $5 \mathrm{~kg}(49.05 \mathrm{~N})$ and $10 \mathrm{~kg}(98.1 \mathrm{~N})$. Test results show that at a normal load of $5 \mathrm{~kg}(49.05 \mathrm{~N})$, the wear rate of the specimen was considerably less at the range of $1.38 \times 10^{-6} \pm 6.90 \times 10^{-8} \mathrm{~g} / \mathrm{Nm}$ and at higher loads of $10 \mathrm{~kg}$ $(98.1 \mathrm{~N})$, the wear rate of the specimens tend to decrease further to $8.66 \times 10^{-7} \pm 4.33 \times 10^{-8} \mathrm{~g} / \mathrm{Nm}$

\subsubsection{Normal load of $5 \mathrm{~kg}$}

Worn surface morphology of the sintered specimen is shown in Figure (5). Figure 5 (a) shows the delamination instigated by removal of the surface by the counter disc where the particles were removed as platelets and chips.
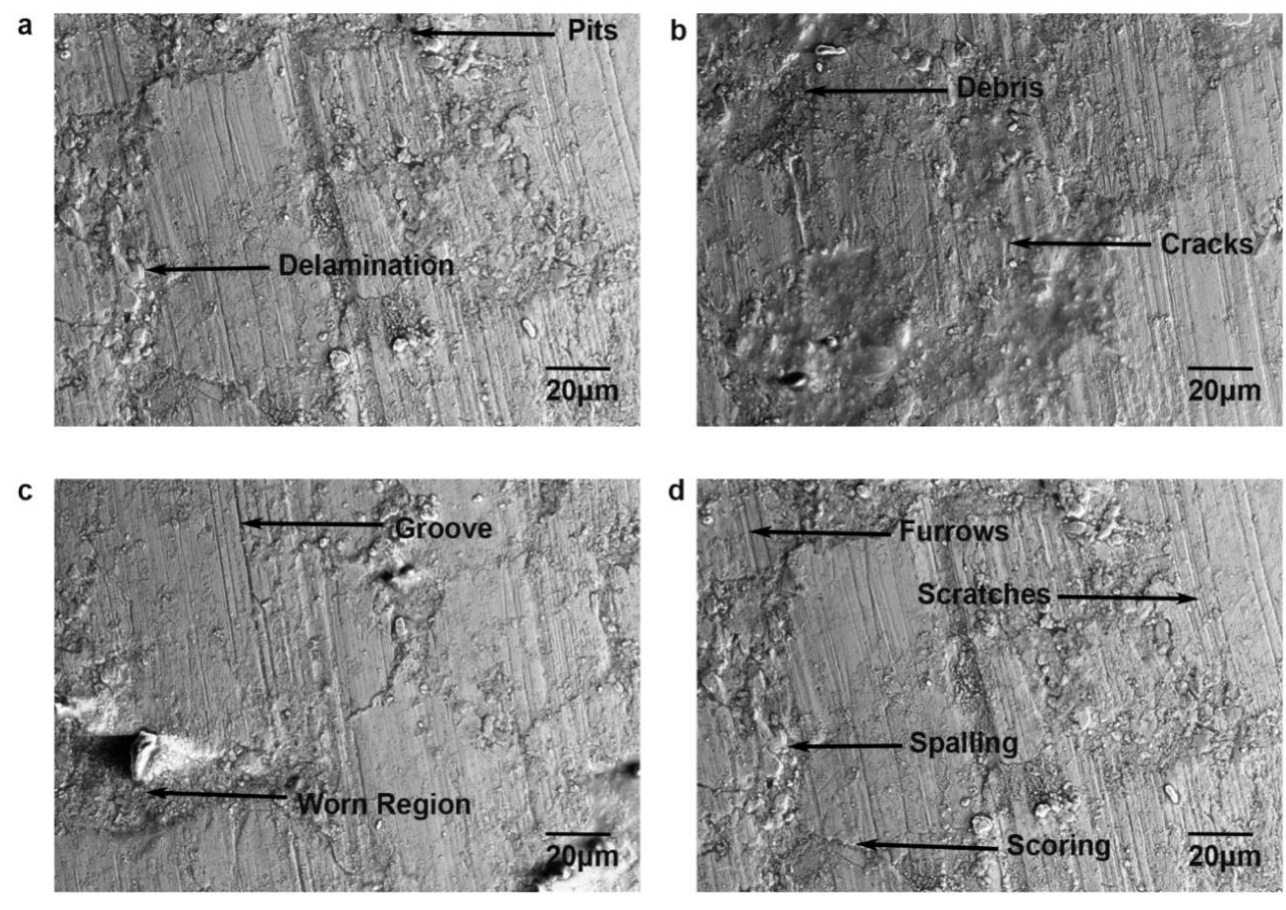

Figure 5. Surface morphology of the worn FGM at a normal load of $5 \mathrm{~kg}$.

Hard particles in the material are abraded away from the surface that leads to the formation of pits. Figure 5 (b) shows the crack generation on the worn surface and accumulation of wear debris. Worn region and groove are shown in the Figure 5 (c). Figure 5 (d) shows furrows, scratches, spalling and scoring. Furrows and scratches caused due to the dragging of hard particles when the material slides against the counter face. The ejection of material from the surface in the form of platelets leads to spalling, and the wear produced furrows and scratches leads to scoring [21-23].

\subsubsection{Normal load of $10 \mathrm{~kg}$}

Characterization of the surface worn at a normal load of $10 \mathrm{~kg}$ is shown in Figure (6). Figure 6 (a) shows delamination due to the repeated stress and cyclic load at a confined spot that leads to the material ejection from the surface and tiny hollow spots as pits.

Wear debris accumulation is indicated in Figure 6 (b). Figure 6 (c) shows spalling and arc crater. During the wear process, a depression on the surface (spalling) caused an account of material removal as a piece of coatings and chips. Figure 6 (d) shows furrows, cracks, and scratches, which is due to the sliding of the worn out pieces between the mating surfaces repeatedly under the influence of high stress and load. 

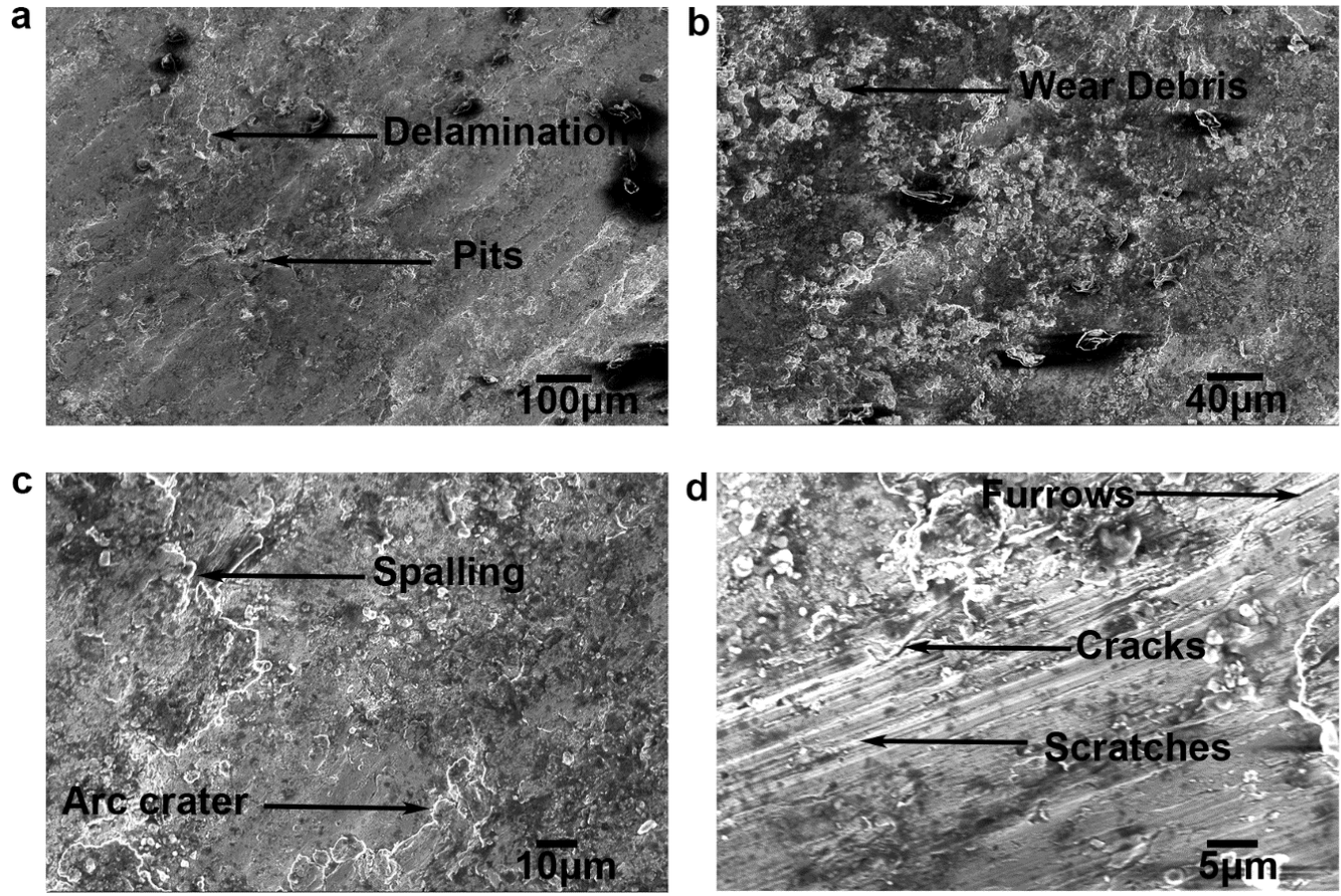

Figure 6. Surface morphology of the worn FGM at a normal load of $10 \mathrm{~kg}$.

\subsubsection{COF}

Pin-on-disc wear test rig was used to perform the wear tests of the FGMs. Specimens were mounted against the counter disc made of EN-31 steel at a normal load of $5 \mathrm{~kg}$ and $10 \mathrm{~kg}$ at sliding speeds of $5.5 \mathrm{~m} / \mathrm{s}$. From the test results, it is obvious that at a normal load of $5 \mathrm{~kg}$, the specimen exhibits a decreased COF value of 0.25 and at greater loads of $10 \mathrm{~kg}$, the COF value tends to increase drastically to the value of 0.55 .

\section{Conclusion}

Functionally gradient material was synthesized successfully for wind turbine friction material application through powder metallurgy technique.

The results reveals the following

-Microstructure of the layered FGM illustrates the gradient layers and the dispersion of hard particles homogeneously in the matrix.

- Hardness range of the FGM progressively burgeons along the cross-section, and the highest hardness of $137 \mathrm{Hv}$ was obtained at the peak.

-At a normal load of $5 \mathrm{~kg}$, a decrease in wear rate was obtained, and further there was an observance of a decreasing trend in wear rate, when the load was increased to $10 \mathrm{~kg}$. On the other hand, the COF is around 0.2 at lower loads, and at higher loads, the COF is around 0.5.

\section{Acknowledgement}

The authors thank Department of Science and Technology, Government of India for the financial support to carry out the research through the project " DST-AMTDEVELP,FT,PP\&TD/2018-19/R/C/150.

\section{References}

[1] E. Junior, J. A. Lewis, F. E. Arrieche, and L. Schaeffer: Analysis of wear in organic and sintered friction materials used in small wind energy converters, Materials Research, 11 (2008), 269-273.

[2] E. Surojo, V. Malau, and M. Ilman: Effects of phenolic resin and fly ash on coefficient of friction of brake shoe composite, J. Eng. Appl. Sci, 9 (2014), 2234-2240. 
[3] P. Balamurugan and M. Uthayakumar: Influence of process parameters on Cu-Fly ash composite by powder metallurgy technique," Materials and Manufacturing Processes, 30 (2015), 313-319.

[4] S. Mohanty and Y. Chugh: Development of fly ash-based automotive brake lining Tribology International, 40 (2007), 1217-1224.

[5] S. Kang: A study of friction and wear characteristics of copper-and iron-based sintered materials Wear, 162 (1993), 1123-1128.

[6] K. Narasimhan: Sintering of powder mixtures and the growth of ferrous powder metallurgy Materials Chemistry and Physics,67 (2001), 56-65.

[7] V. Merie, V. Cândea, C. Bîrleanu, P. Păşcuţă, and C. Popa: The influence of titanium dioxide on the tribological characteristics of a Fe-based friction composite material Journal of Composite Materials, 48 (2014), 235-243.

[8] M. Chandrasekaran and P. Singh: Sintered iron-copper-tin-lead antifriction materials-effect of temperature Materials Science and Engineering: A, 292 (2000), 26-33.

[9] P. Gupta, D. Kumar, O. Parkash, and A. Jha: Hardness and wear behavior of CoO doped Fe-Al2O3 metal matrix composite (MMC) synthesized via powder metallurgy (P/M) technique in Advanced Materials Research, (2012), 584-589.

[10] H. Ö. Gülsoy, M. K. Bilici, Y. Bozkurt, and S. Salman: Enhancing the wear properties of iron based powder metallurgy alloys by boron additions Materials \& design, 28 (2007), 2255-2259.

[11] S. Tekeli and A. Güral, Dry sliding wear behaviour of heat treated iron based powder metallurgy steels with 0.3\% Graphite+ 2\% Ni additions, Materials \& design, 28 (2007) ,1923-1927.

[12] K. Gopinath: The influence of speed on the wear of sintered iron-based materials ,Wear, 71 (1981), 161-178,

[13] T. R. Prabhu, V. Varma, and S. Vedantam: High-speed tribological and mechanical properties of layered $\mathrm{Fe} / \mathrm{SiC}$ composites, Journal of materials engineering and performance, 23 (2014), 3666-3679.

[14] A. N. M. Negari, R. Mamoory, A. Simchi, and N. Ehsani: Determination of the physical and mechanical properties of iron-based powder materials produced by microwave sintering, Powder Metallurgy and Metal Ceramics, 46 (2007), 423-428.

[15] I. Peter and M. Rosso: Study and optimization of metal based sintered materials for automotive brake friction production, in Solid State Phenomena, (2016), 20-26.

[16] C. Krishnamurthy Srinivasa, C. Suryanarayana Ramesh, and S. Prabhakar: Blending of iron and silicon carbide powders for producing metal matrix composites by laser sintering process, Rapid Prototyping Journal, 16 (2010), 258-267,

[17] U. Cavdar, B. S. Unlu, and E. Atik: Effect of the copper amount in iron-based powder-metal compacts, Materiali in tehnologije, 48 (2014) 977-982.

[18] L. De Oliveira, R. d. R. Paranhos, R. d. S. Guimaraes, G. Bobrovnitchii, and M. Filgueira: Use of PM $\mathrm{Fe}-\mathrm{Cu}-\mathrm{SiC}$ composites as bonding matrix for diamond tools, Powder metallurgy, 50 (2007),148-152.

[19] K. Gan, M. Gu, and G. Mu: Effect of Fe on the properties of Cu/SiCp composite, Journal of Materials Science, 43 (2008), 1318-1323.

[20] O. Y1lmaz: Abrasive wear of $\mathrm{FeCr}$ (M7C3-M23C6) reinforced iron based metal matrix composites, Materials Science and Technology, 17 (2001),1285-1292.

[21] Vaira Vignesh Ramalingam, Padmanaban Ramasamy, Mohan Das Kovukkal, Govindaraju Myilsamy: Research and Development in Magnesium Alloys for Industrial and Biomedical Applications: A Review, Metals and Materials International.

[22] K. Rajesh Kannan, R.Vaira Vignesh, Kota Pavan Kalyan,Jayaprakash Murugesan, A. Megalingam, R. Padmanaban, and M. Govindaraju : Tribological performance of heavy-duty functionally gradient friction material (Cu-Sn-Fe-Cg-SiC-Al2O3) synthesized by PM Route AIP Conference Proceedings, 2128(2019), 020004.

[23] K. Subbaiah, M. Geetha, M. Govindaraju S.R.Koteswara Rao : Mechanical Properties of Friction Stir Welded Cast Al-Mg-Sc Alloys Transaction of the Indian Institute of Metals, 65 (2) (2012), 155-158. 